\title{
МОДЕЛИРОВАНИЕ И РАСЧЕТ СХЕМ ПОГАШЕНИЯ КРЕДИТА
}

@ А.И. Кузнецов

aleksander2055@mail.ru

Кузнецов А.И. УДК 517.518

DOI: 10.33184/mnkuomsh2t-2021-10-06.82.

Актуальность потребительского кредитования обусловливается тем, что развитие области потребительского кредитования способствует ускоренному развитию не только потребительского рынка, но и банковского сектора экономики, что способствует росту экономики нашей страны в общем, а также увеличению качества и жизненного уровня российских граждан.

Ключевые слова: математика, финансовая математика, потребительское кредитование.

\section{Modeling and calculation of loan repayment schemes}

The relevance of consumer lending is due to the fact that the development of consumer lending contributes to the accelerated development of not only the consumer market, but also the banking sector of the economy, which contributes to the growth of the economy of our country in general, as well as to an increase in the quality and living standards of Russian citizens.

Keywords: mathematics, financial mathematics, consumer lending.

В настоящее время в нашей стране наблюдается стремительное развитие рынка кредитования населения. Объемы предоставленных физическим лицам кредитов продолжают увеличиваться, несмотря на то, что многие кредитные организации всячески стараются утаивать от потенциального заемщика реальную стоимость кредита на стадии оформления кредитной заявки.

Потребительский кредит относится к одному из наиболее распространенных вариантов банковских операций в большинстве стран. Кроме этого, сфера применения потребительского кредита является более широкой, чем просто приобретение товаров длительного пользования, например, таких как автомобилей, бытовой техники. . . Он приобрел достаточно широкое распространение в развитых странах в основном из-за того, что при применении данной технологии финансирования покупок происходит значительное расширение рынка по внушительному спектру потребительских товаров, а также недвижимости.

Кузнецов Александр Игоревич, студент, БашГУ (Уфа, Россия); Aleksander Kuznetsov, student (Bashkir State University, Ufa, Russia) 
Реализованная программа помогает легко и быстро рассчитать затраты на приобретение кредита у любого банка.

Кредитный калькулятор - инструмент расчета стоимости кредита, который позволяет рассчитать кредит, определить сумму ежемесячного платежа и построить график платежей до окончания срока кредитования. С помощью данного калькулятора, можно выяснить какой размер выплаченной суммы пошел на погашение кредита, а какой на погашение процентов. Используя калькулятор, можно определить полный размер выплат по уже взятому или запланированному кредиту в зависимости от вида платежа. Кредитный калькулятор предоставляет возможность произвести расчеты для аннуитетного и дифференцированного платежей.

Несомненным достоинством программы является ее универсальность. В первую очередь, это относится к просчету условий разных банков.

В результате вычислений выявлено, что погашение кредита «Равными срочными выплатами» для заемщика является более невыгодным, по сравнению с погашением кредита по схеме «Равными долями от общей суммы долга»

\section{Литература}

1. Четыркин E.M. Методы финансовых и коммерческих расчетов - Издательство: Дело.,1995. - 320 с.

2. Люу Ю.Д. Методы и алгоритмы финансовой математики - пер. Бином: Лаборатория знаний,2007. - 738 с.

3. Брусов П.Н. Финансовая математика. - М.: Инфра-М,2014. - 480 с. 